\title{
Smart Smoke Detector
}

\section{Mohamad Syafiq Mohamad Adenan ${ }^{1}$, Athirah Nabihah Mas Erwan ${ }^{1}$, Mohamad Norul Hafiz Muzaffar Alfian ${ }^{1}$}

${ }^{1}$ Program of Computer Science, Department of Computing, Faculty of Arts, Computing and Creative Industry. Universiti Pendidikan Sultan Idris, Malaysia.

Article history

Received:

14.01.2021

Revised:

12.03.2021

Accepted:

18.03.2021

*Corresponding Author: Mohamad Syafiq Mohamad Adenan

Email:

syafiqadnan@gmail.com

This is an open access article, licensed under: $\mathrm{CC}-\mathrm{BY}-\mathrm{SA}$

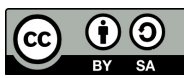

Abstract: In the past few decades many studies and researches have taken place in order to improve security systems and to increase their level of protection in different fields. One of the major problems that security must deal with is the fire outbreak that can happen in everywhere including houses, schools, factories and many other places, and to avoid that or to minimize the damage caused by fire outbreak an IoT technology is used to control such a kind of risk. IoT is a modern system that consist of sensors and switches connected. In this research we will use temperature sensor known as (Flame sensor) with Arduino device to detect fire outbreak and to measure the amount of heat intensity generated by a fire outbreak or in a specific location in our house, offices and other places. It sometimes takes too much time for the fire station to reach to the fire outbreak location and works on extinguish the fire and so these sensors will work as an early alarm system which will send a notification to our mobile phones if any fire outbreak occurred to let us know the situation clearly and before it's too late, we act to avoid significant damage in case the fire outbreak was observed after a long time from its outbreak.

Keywords: Arduino, Fire, Flame Sensor, Industrial Revolution 4.0, Internet of Things. 


\section{Introduction}

Fire is very deadly and it leads to loss of human life and property. Fire detection systems are necessary to reduce the destruction of personal belongings and caused by fire both man-made and induced. The National Crime Records Malaysia indicates that there has been a total of 6,626 fatalities due to fire accidents during the years 2018. Thankfully by the usage of more smart fire detecting systems the number of fire accidents have been reducing steadily. One of the most destructive properties of fire is that it spreads exponentially and with the right medium can spread uncontrollably [1].

This is why timely detection of fire is necessary for avoiding a fire hazard. The Internet of Things is a collection of sensors, actuators, software, electronics embedded with home appliances, physical devices and vehicles which connect with each other to connect and exchange date which helps in increasing the efficiency of everyday appliances using computer-based systems. Not only does it help in improving the efficiency of a device but also has economic benefits. IoT is just another way to make everyday life easier for humans by developing smart devices. IoT devices have increased $31 \%$ per and was at 8.4 billion in the year 2017. The total count is set to reach 30 billion devices by the year 2020. This research is been developed to reduce the damage caused by fires. In addition, this research can make it easier for firefighters to know the location of the fire before it spreads even larger.

\section{Literature Review}

\subsection{Internet of Things}

In the past few years, Internet of Things have been utilized in many fields to improve quality of activities. The idea of using sensors and internet combined with physical devices turns out bring lot of benefits. Some of the interesting research using IoT can be seen below:

- Zariman, et al [2] develop a garbage monitoring using Arduino and ESP WiFi that can be used in the garbage management system in the city.

- Azahar, et al [3] develop intelligent egg incubator using Arduino Uno, PIR Sensor, and ESP8266 that can be used to control the temperature of the incubator.

- Ismail, et al [4] develop smart water level indicator using Arduino Uno, Servo Motor, and NodeMCU ESP32 that can be used to provide early warnings and control the dam of the river.

- Husin and Hisham [5] develop smart charger that can be used to control the charging time to preserve battery lifetime.

- Latif, et al [6] develop smart mirror using Arduino Uno, Raspberry Pi 3, and NodeMCU that can be used to provide latest news updates while the user do activity in front of mirror.

- Ghani and Zariman [7] develop smart cane to help provide safe navigation for user with vision disability.

- Hazhari, et al [8] develop smart delivery that help delivery items faster.

- Azizi and Zariman [9] develop health display based on ESP 8266 NodeMCU and pulse sensor to help display pulse rate.

- Saidatin, et al [10] develop automate feeder using ESP 8266 to help feeding birds.

- Hermansyah, et al [11] develop a remote monitoring and control system to switch main energy source to backup when main source goes out.

\subsection{Structure Fire}

A structure fire is a fire involving the structural components of various residential buildings ranging from single-family detached homes and townhouses to apartments and tower blocks, or various commercial buildings ranging from offices to shopping malls. This is in contrast to "room and contents" fires, chimney fires, vehicle fires, wildfires or other outdoor fires [12]. Structure fires typically have a similar response from the fire department that include engines, ladder trucks, rescue squads, chief officers, and an EMS unit, each of which will have specific initial assignments.

Structure Fire has many types of variation [13] such as:

1. Fire-Resistive

Structures are high-rises, and they're the stoutest of all construction types when exposed to fire. High-rises are usually defined as buildings more than 75 feet tall, with some agencies making amendments for buildings that are 35-55 feet tall.

2. Non-Combustible 
Construction is typically found in new buildings and remodels of commercial structures. The walls and roofs are constructed of non-combustible materials. Specifically, walls are usually reinforced masonry or tilt slab, while roofs have metal structural members and decking. The top of these roofs are often covered with lightweight concrete, foam, an insulated membrane or a combination of these materials. Because most of these buildings are newer builds, they're usually up to code and include fire suppression systems. And because metal roofs may fail with heat not just from direct fire expect early collapse, especially in some of the bigger buildings that have a substantial fire load.

3. Ordinary

Buildings can be of either new or old construction, and they have non-combustible walls and a wood roof. Older construction buildings may consist of unreinforced masonry and have a conventionally framed roof, while newer buildings will have lightweight roof systems supported by reinforced masonry or tilt slab. The most common types of roof systems in a commercial setting of construction include parallel cord truss and panelised roof systems, plants and animals due to its extreme heat. Thirdly, volcanic ash, generally meaning the cooled ash, may form a cloud, and settle thickly in nearby locations.

4. Heavy Timber

Construction is found in older buildings and utilizes large dimensional lumber for structural members and interior elements. These buildings hold up well under fire conditions, but it's critical that firefighters not feel a false sense of security, as these buildings are often poorly maintained, or have termites and/or weathering issues that can contribute to an earlier-thanexpected collapse.

5. Wood-Framed

Construction is found in many modern homes. The walls and roofs are made of combustible materials - most commonly wood. If the walls are wood-framed, the roof usually is as well. Rooftops are ceramic tile or asphalt shingles placed over lightweight trusses and OSB. Both UL and NIST studies have found that lightweight construction will fail within minutes of direct fire impingement.

\subsection{Effect of Structure Fire}

Fires impact people, property and the environment in all countries around the world. In some cases, the resulting losses are extraordinary, causing hundreds of deaths, widespread damage to property and contents and significant impacts on the environment. More often, fires may cause a single casualty or affect a single home, though the effects are still highly significant to those affected and collectively are substantial [14].

\subsection{Component of Smoke Detector}

Nowadays, we can see a lot of research that implied IoT concept. There are many devices that the developer used to build an IoT research. For this section will focus on the famous IoT platform that popular among IoT developer which is Arduino Mega and other components.

\subsubsection{Arduino Mega}

The Arduino Mega 2560 is a microcontroller board based on the ATmega 2560. It has 54 digital input/output pins (of which 14 can be used as PWM outputs), 16 analog inputs, 4 UARTs (hardware serial ports), a $16 \mathrm{MHz}$ crystal oscillator, a USB connection, a power jack, an ICSP header, and a reset button. It contains everything needed to support the microcontroller; simply connect it to a computer with a USB cable or power it with an AC to DC adapter or battery to get started [15]. The Mega is compatible with most shields designed for the Arduino Duemilanove or Diecimila.

\subsubsection{Flame Sensor}

A sensor which is most sensitive to a normal light is known as a flame sensor. That's why this sensor module is used in flame alarms. This sensor detects flame otherwise wavelength within the range of $760 \mathrm{~nm}-1100 \mathrm{~nm}$ from the light source [16]. This sensor can be easily damaged to high temperature. So, this sensor can be placed at a certain distance from the flame. The flame detection can be done from a $100 \mathrm{~cm}$ distance and the detection angle will be 600 . The output of this sensor is an analog signal or digital signal. 
A flame-sensor is one kind of detector which is mainly designed for detecting as well as responding to the occurrence of a fire or flame. The flame detection response can depend on its fitting. It includes an alarm system, a natural gas line, propane \& a fire suppression system. This sensor is used in industrial boilers. The main function of this is to give authentication whether the boiler is properly working or not. The response of these sensors is faster as well as more accurate compare with a heat/smoke detector because of its mechanism while detecting the flame.

\subsubsection{MQ-2 Gas Sensor}

Sensitive material of MQ-2 gas sensor is $\mathrm{SnO}$, which with lower conductivity in clean air. When the target combustible gas exists, the sensor's conductivity is higher along with the gas concentration rising [17]. Please use simple electro-circuit, convert change of conductivity to correspond output signal of gas concentration. MQ-2 gas sensor has high sensitivity to LPG, Propane and Hydrogen, also could be used to Methane and other combustible steam, it is with low cost and suitable for different application.

\subsubsection{Buzzer 5V}

A 5V Active Alarm Buzzer Module for Arduino is an audio signaling device, which may be mechanical, electromechanical, or piezoelectric. Just like what you are viewing now, it is $5 \mathrm{~V}$ DC Electronic Part Active Buzzer Module. Using top quality material, it is durable in use.

What is more, an active buzzer rings out as long as it is electrified. Compared with a passive buzzer, it is a bit expensive but easier to control. Typical uses of buzzers include alarm devices, timers, and confirmation of user input such as a mouse click or keystroke.

\subsubsection{Breadboard}

A breadboard is a solderless device for temporary prototype with electronics and test circuit designs. Most electronic components in electronic circuits can be interconnected by inserting their leads or terminals into the holes and then making connections through wires where appropriate.

\subsubsection{Light Emitting Diode}

Light Emitting Diode (LED) is a semiconductor device that emits visible light when an electric current passes through it. The light is not particularly bright, but in most LEDs it is monochromatic, occurring at a single wavelength. The output from an LED can range from red (at a wavelength of approximately 700 nanometers) to blue-violet (about 400 nanometers). Some LEDs emit infrared (IR) energy (830 nanometers or longer); such a device is known as an infrared-emitting diode (IRED).

\subsubsection{ESP 8266}

ESP8266 offers a complete and self-contained Wi-Fi networking solution, allowing it to either host the application or to offload all Wi-Fi networking functions from another application processor. When ESP8266 hosts the application, and when it is the only application processor in the device, it is able to boot up directly from an external flash. It has integrated cache to improve the performance of the system in such applications, and to minimize the memory requirements.

\section{Methodology}

Based on the study, the author compared 3 methodologies to produce this research. The methodology being compared is Prototyping, Agile and Spiral Model [18] [19] [20].

For this research, we chose to use Prototype methodology. The reason why this methodology was chosen is that the basic idea in this methodology is that instead of freezing the requirements before a design or coding can proceed, a throwaway prototype is built to understand the requirements. This prototype is developed based on the currently known requirements. Prototype methodology is defined as a Software Development model in which a prototype is built, test, and then reworked when needed until an acceptable prototype is achieved. It also creates a base to produce the final system Software prototyping model works best in scenarios where the research's requirement is unknown. It is an iterative, trial, and error method which take place between the developer and the client. 
Table 1. Comparison and Description of Methodology

\begin{tabular}{|c|c|c|c|}
\hline TYPE & PROTOTYPING & AGILE & SPIRAL MODEL \\
\hline 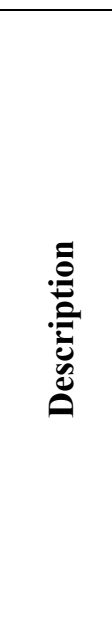 & $\begin{array}{l}\text { A prototyping model is a } \\
\text { systems development } \\
\text { method in which a } \\
\text { prototype (an initial } \\
\text { approximation of a final } \\
\text { system or product) is built, } \\
\text { tested and then reworked } \\
\text { as necessary until an } \\
\text { acceptable prototype is } \\
\text { finally achieved from } \\
\text { which the complete system } \\
\text { or product can now be } \\
\text { developed. }\end{array}$ & $\begin{array}{l}\text { In Agile, development is } \\
\text { divided into small } \\
\text { iterations which are called } \\
\text { Sprints. This is a better } \\
\text { development methodology } \\
\text { due to its continuous } \\
\text { planning, testing, } \\
\text { integration, risk evaluation } \\
\text { and control on the progress } \\
\text { of the research and there } \\
\text { upon reduces the chances } \\
\text { of research failure. }\end{array}$ & $\begin{array}{l}\text { Spiral model is a risk- } \\
\text { driven } \\
\text { development poftware } \\
\text { model. Based on the } \\
\text { unique risk patterns of a } \\
\text { given research, the spiral } \\
\text { model guides a team to } \\
\text { adopt elements of one or } \\
\text { more process models such } \\
\text { as incremental, waterfall } \\
\text { or evolutionary proto- } \\
\text { typing. }\end{array}$ \\
\hline 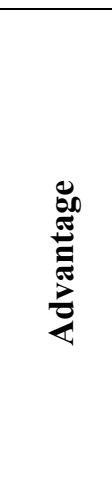 & $\begin{array}{l}\text { - Obtain user feedbacks in } \\
\text { initial stages of research. } \\
\text { - Initial research estimate } \\
\text { that either the research can } \\
\text { successfully meet the } \\
\text { deadlines or not. } \\
\text { - It reduces the expenses. } \\
\text { - It also allows to make } \\
\text { changings in finished } \\
\text { product. }\end{array}$ & $\begin{array}{l}\text { - Agile is a flexible } \\
\text { methodology. } \\
\text { - Agile is very } \\
\text { accommodative to changes. } \\
\text { - Agile methodology caters } \\
\text { the ever-changing } \\
\text { requirements. } \\
\text { - Its rapid delivery helps to } \\
\text { satisfy customers. }\end{array}$ & $\begin{array}{l}\text { - The process of } \\
\text { development is fast. } \\
\text { - There is control towards } \\
\text { all phases of development. } \\
\text { - Customer feedback is } \\
\text { taken into consideration } \\
\text { and changes implemented } \\
\text { as soon as possible. } \\
\text { - Many and more features } \\
\text { are added systematically. }\end{array}$ \\
\hline 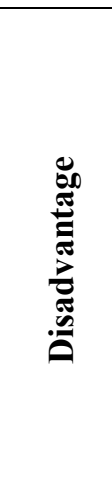 & $\begin{array}{l}\text { - It is a slow processing } \\
\text { methodology. } \\
\text { - This system first lead to } \\
\text { implementation of system } \\
\text { and then repairing way. } \\
\text { - This is a complex system } \\
\text { and scope of system } \\
\text { expands beyond the } \\
\text { original plans. }\end{array}$ & $\begin{array}{l}\text { - If the research manager } \\
\text { is not experienced, then } \\
\text { research can become a } \\
\text { large series of sprints, and } \\
\text { come in late and over } \\
\text { budget. } \\
\text { - This is a less predictable } \\
\text { process about researchs } \\
\text { output (final product isn't } \\
\text { defined clearly). }\end{array}$ & $\begin{array}{l}\text { - It is very much costly for } \\
\text { smaller researchs. } \\
\text { - The requirements } \\
\text { documentation could be } \\
\text { lengthy as it has } \\
\text { intermediate phases. } \\
\text { - The risk analysis phase } \\
\text { requires an expert } \\
\text { authority to make the } \\
\text { analysis. }\end{array}$ \\
\hline
\end{tabular}

Prototyping is used to allow the users evaluate developer proposals and try them out before implementation. It also helps understand the requirements which are user specific and may not have been considered by the developer during product design. Figure 1 shows the stepwise approach in design a software by using prototyping model.

\subsection{Requirement Gathering and Analysis Phase}

A prototyping model starts with requirement analysis. In this phase, the requirements of the system are defined in detail. During the process, the users of the system are interviewed to know what their expectations from the system are. Author make a google form and ask public about every function about the research. 


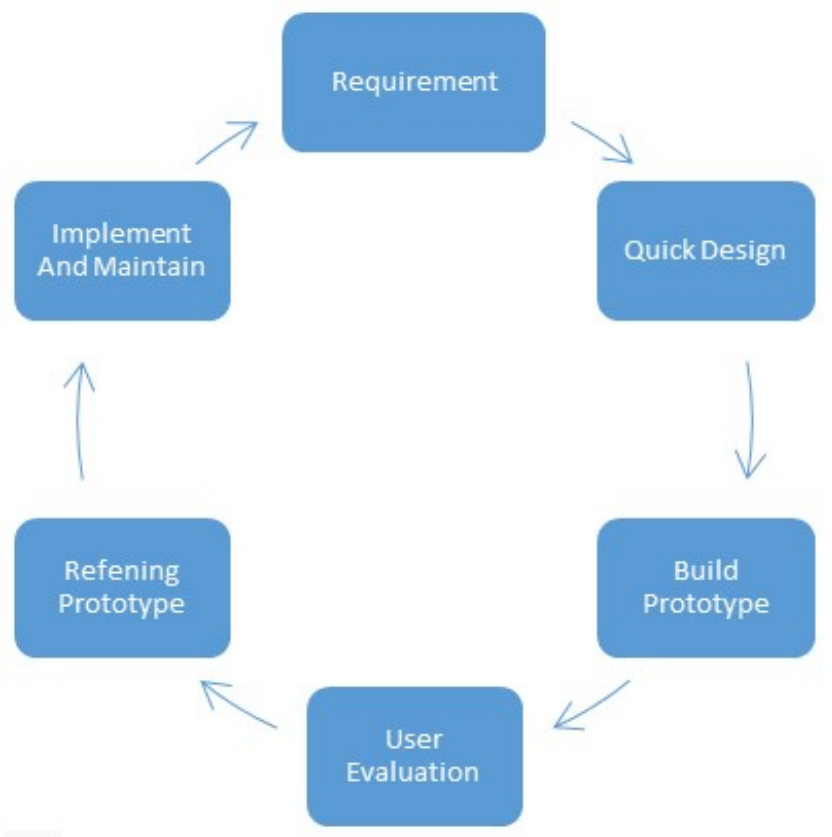

Figure 1. Prototype Methodology Diagram

\subsection{Quick Design}

The second phase is a quick design. In this stage, a simple design of the system is created. It gives a brief idea of the system to the user. This phase helps in developing the prototype. Figures 2 show the sketch diagram of the research.

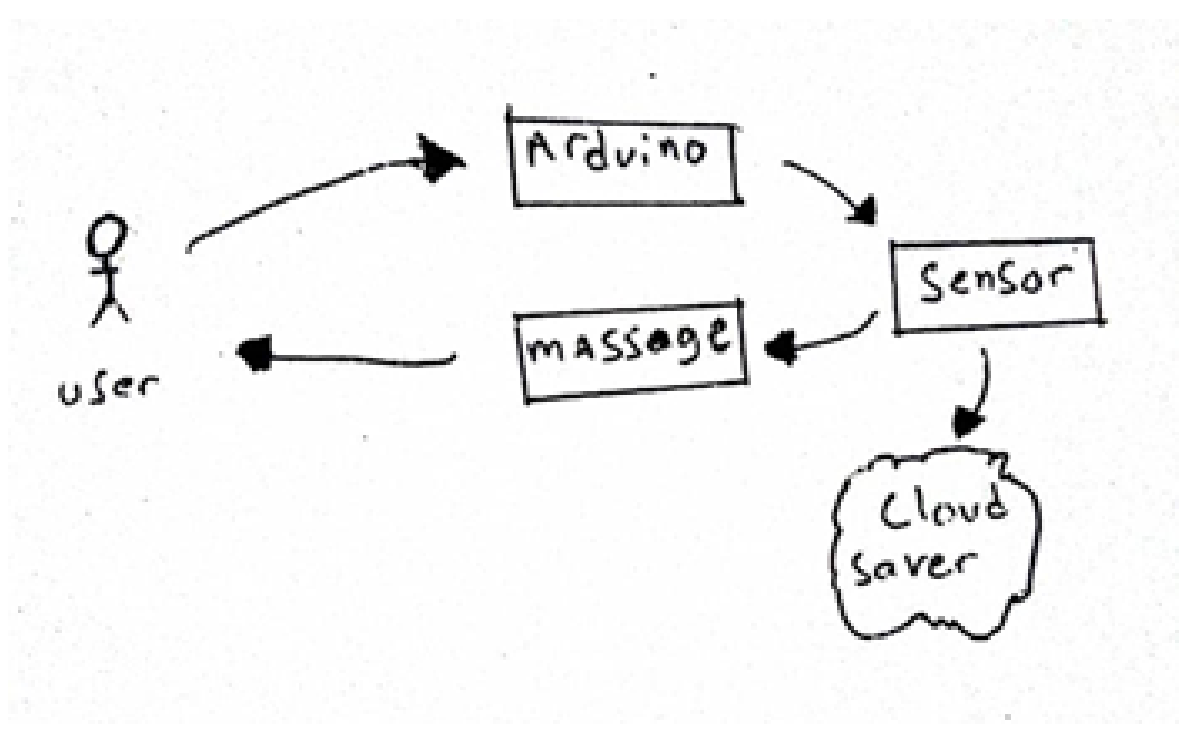

Figure 2. Sketch of Smoke Detector with IoT Notifications

\subsection{Build Prototype Phase}

In this phase, an actual prototype is designed based on the information gathered from quick design. It is a small working model of the required system. 
Table 2. Method of Building the Research

\begin{tabular}{|c|c|}
\hline Step & Description \\
\hline Step 1 & $\begin{array}{l}\text { Study well about the background of this research and IoT research. We have to } \\
\text { understand what IoT researchs and how it's work. Prepare all the hardware } \\
\text { requirements, software requirements and the components that used for these } \\
\text { researchs. First of all, we need the components, then we have to download the } \\
\text { arduino IDE software to run the arduino. }\end{array}$ \\
\hline \multirow[t]{9}{*}{ Step 2} & $\begin{array}{l}\text { Once done installing it, we can try all our components either all of that working } \\
\text { well or not. Then, we have to check MQ-2 sensor and Flame sensor work or } \\
\text { not in arduino board. Then, upload the coding using the arduino IDE Software. } \\
\text { We can get the source code. }\end{array}$ \\
\hline & MQ-2 sensor: \\
\hline & Analog pin to $\mathrm{A} 0$ in Arduino board \\
\hline & GND pin to GND pin in Arduino board \\
\hline & VCC pin to VCC pin in Arduino board \\
\hline & Flame sensor: \\
\hline & Analog pin to A1 in Arduino board \\
\hline & GND pin to GND pin in Arduino board \\
\hline & VCC pin to VCC pin in Arduino board \\
\hline Step 3 & $\begin{array}{l}\text { Once done uploading the coding, both sensors will function well. Then prepare } \\
\text { some box or container to cover the sensor and the Arduino. }\end{array}$ \\
\hline Step 4 & $\begin{array}{l}\text { Next, we have to download the Blynk app in our smartphone. Once done } \\
\text { installing Blynk app, it will send the authentication code to our registered } \\
\text { email. We have to save that authentication code. }\end{array}$ \\
\hline \multirow[t]{5}{*}{ Step 5} & $\begin{array}{l}\text { Now is time to setting the NodeMCU to get the internet supply from our } \\
\text { phone. For this, we have to connect both sensor to the NodeMCU. So, it is easy } \\
\text { to detect the fire and smoke and send the notification to the phone. }\end{array}$ \\
\hline & MQ-2 Sensor: \\
\hline & VCC is connected to the $3 \mathrm{~V} 3$ pin in NodeMCU \\
\hline & GND is connected to the GND pin in NodeMCU \\
\hline & Analog Pin is connected to the A0 pin in NodeMCU \\
\hline Step 6 & $\begin{array}{l}\text { Now have to upload the coding. Once done uploading the coding we have to } \\
\text { connect our phone to the NodeMCU. For this it easy to use our own mobile } \\
\text { hotspot. Then we have to open the serial monitor to check either there are got } \\
\text { internet connection or not. }\end{array}$ \\
\hline Step 7 & $\begin{array}{l}\text { After settle with all this procedure, we will get the notifications in phone } \\
\text { through the Blynk app. }\end{array}$ \\
\hline Step 8 & $\begin{array}{l}\text { Last part is to modify or design the smoke detect box to make sure it looks } \\
\text { nice. We also can use any small box to keep the components. }\end{array}$ \\
\hline
\end{tabular}

\subsection{User Evaluation Phase}

In this stage, the proposed system is presented to the client for an initial evaluation. It helps to find out the strength and weakness of the working model. Comment and suggestion are collected from the customer and provided to the developer.

\subsection{Refining Prototype Phase}

If the user is no happy with the current prototype, the prototype is refined according to the user's feedback and suggestions. This phase is not over until all the requirements specified by the user are 
met. Once the user is satisfied with the developed prototype, a final system is developed based on the approved final prototype.

\subsection{Implement Product and Maintain Phase}

Once the final system is developed based on the final prototype, it is thoroughly tested and deployed to production. The system undergoes routine maintenance for minimizing downtime and prevent large-scale failures.

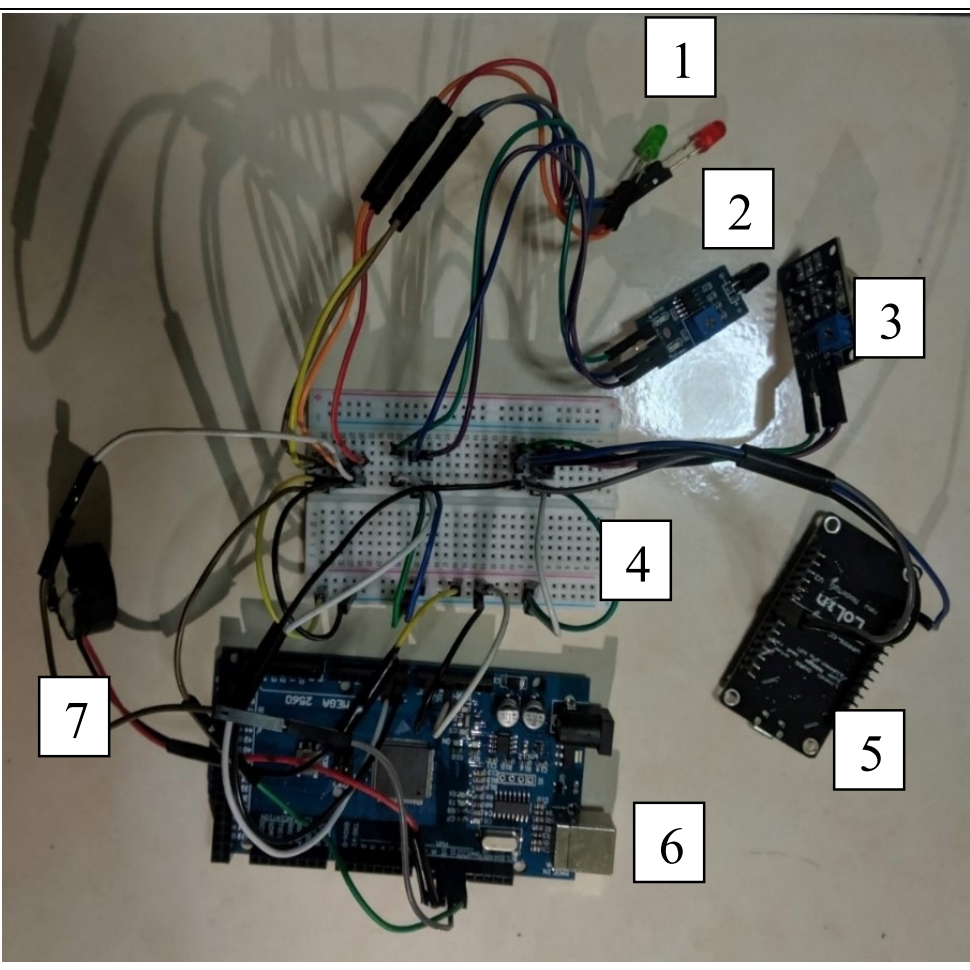

1. LED

2. Flame Sensor

3. MQ-2 Sensor

4. Breadboard

5. NodeMCU (ESP 8266)

6. Arduino Mega

7. Buzzer

Figure 3. System Prototype

\section{Results and Discussion}

\subsection{Implementation}

Implementation is made up of two parts, namely device implementation Hardware and Software implementation.

\subsubsection{Hardware}

Hardware implementation involves the use of the device being used. Know your device's workflow from a microcontroller for reading sensors, relay control and data transmission to the server. Prototype the system has been made visible in Figure 3.

\subsubsection{Software}

Software implementation is intended for deployment and use applications into the system. 
Software Configuration

All of the coding is done in Arduino Ide software. Figure 4 and 5 shows the coding for Arduino Mega and Figure 6 shows coding for NodeMCU (ESP 8266).

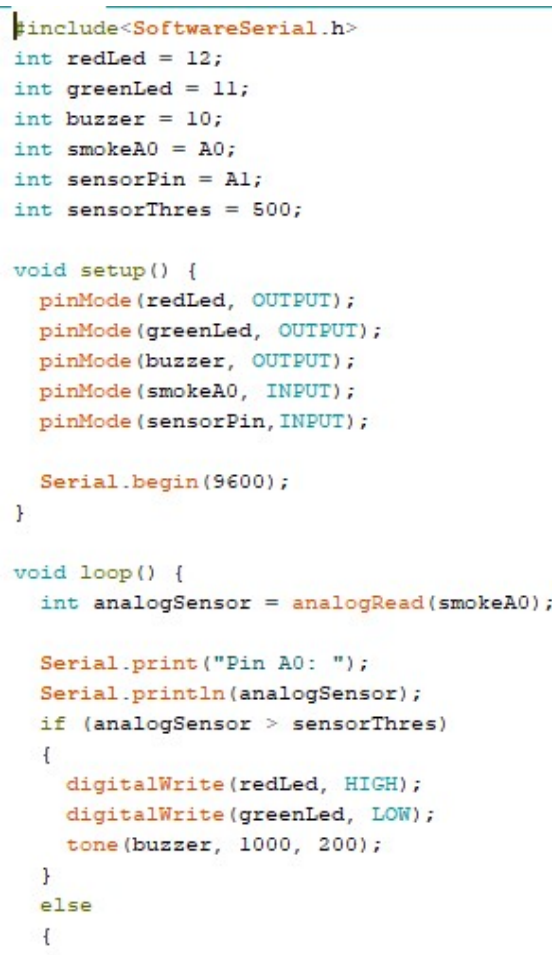

Figure 4. Coding for Arduino Mega (1)

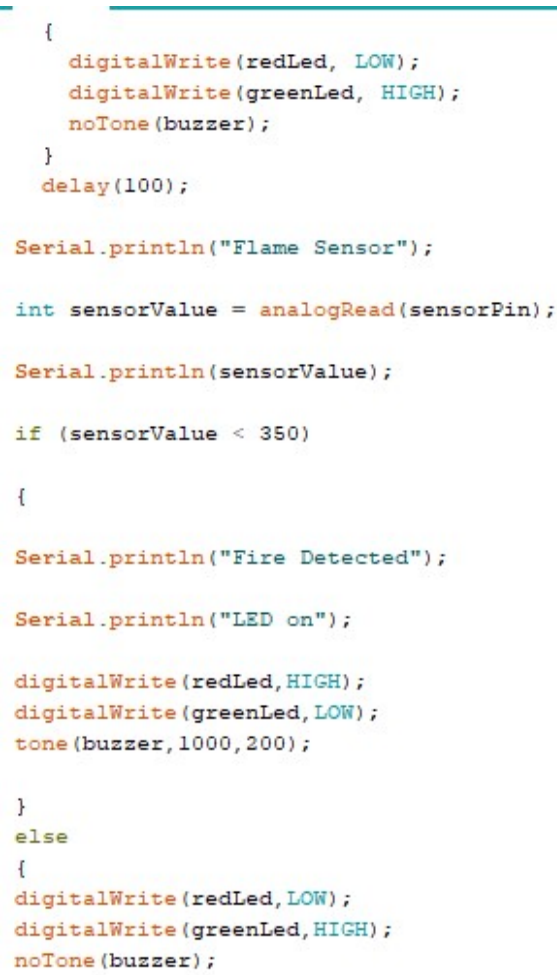

Figure 5. Coding for Arduino Mega (2) 


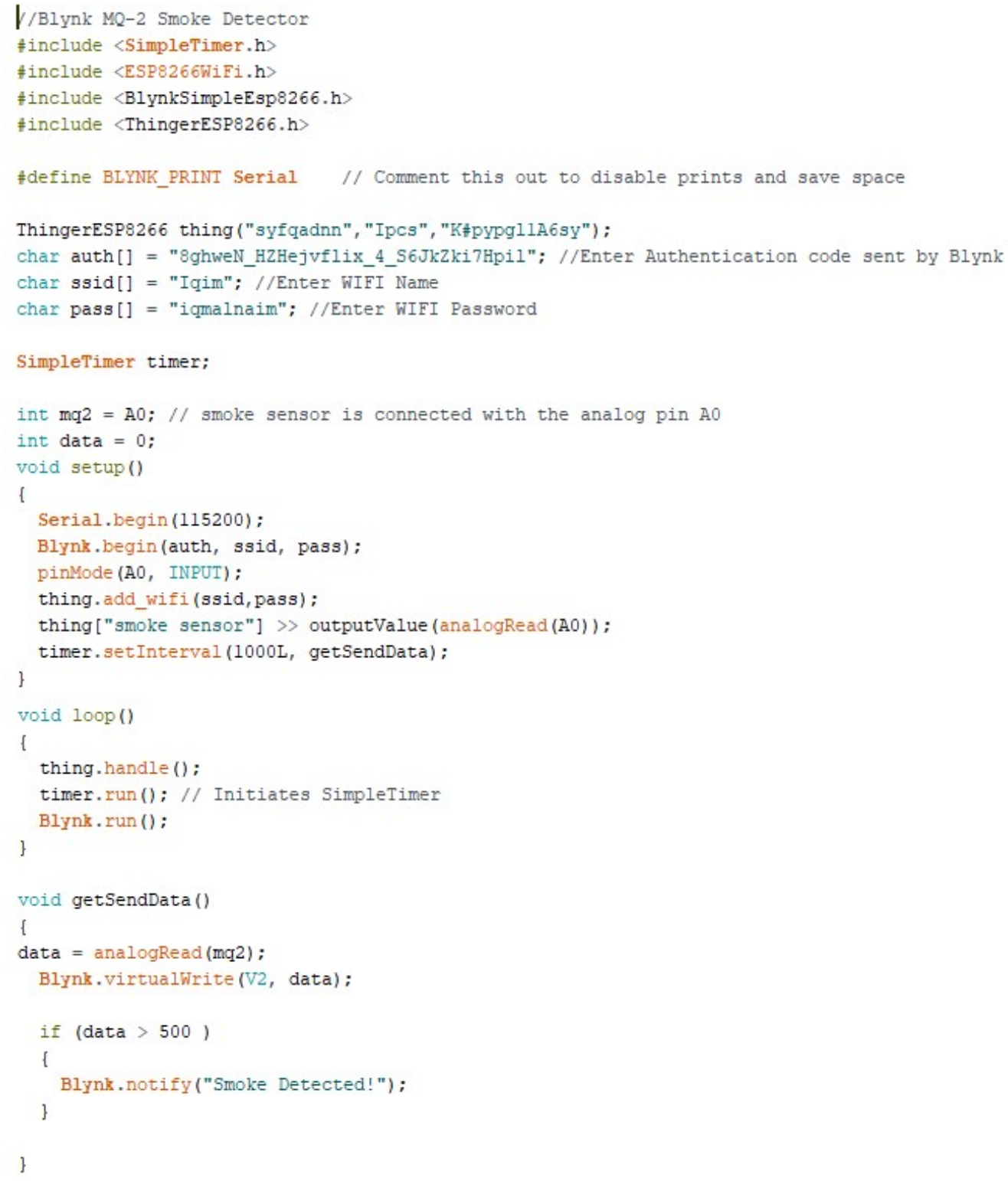

Figure 6. Coding for NodeMCU

\section{Database}

Thinger.io is an Internet of Things platform designed for building vertical applications. It has been designed with the developer in mind, so it is really easy to create IoT solutions from scratch. This is the database software that I worked with and this platform can be freely deployed in your cloud using Ubuntu Core, have Sigfox integration, and can be connected to other microcontrollers or systems for real-time sensing and actuating over a REST API.

The main features of the platform are full device management and API interaction; endpoints for interacting with third party services or sending notifications; data buckets for storing and exporting information; access management for granting to access your devices and data from other applications; and dashboards for real-time data visualization.

\section{Data Visualization}

In this page, it shows all data that the sensor reading in real-time. All the data will show in the graph and gauge. That can adjust base on your research. The important thing is to make sure thinger io connect with your NodeMCU to get real-time data transmission. 


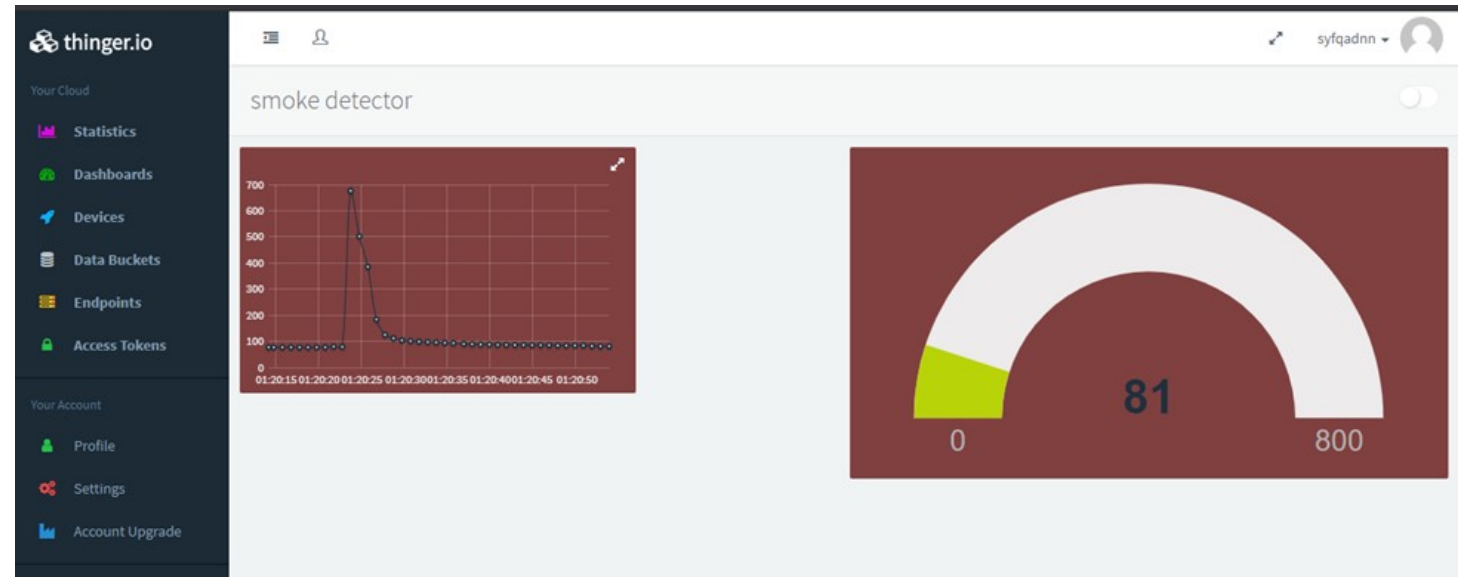

Figure 7. Main Dashboard

\subsection{Testing}

\subsubsection{Testing for the System}

Figure 8 shows the final product of the Smoke Detector.

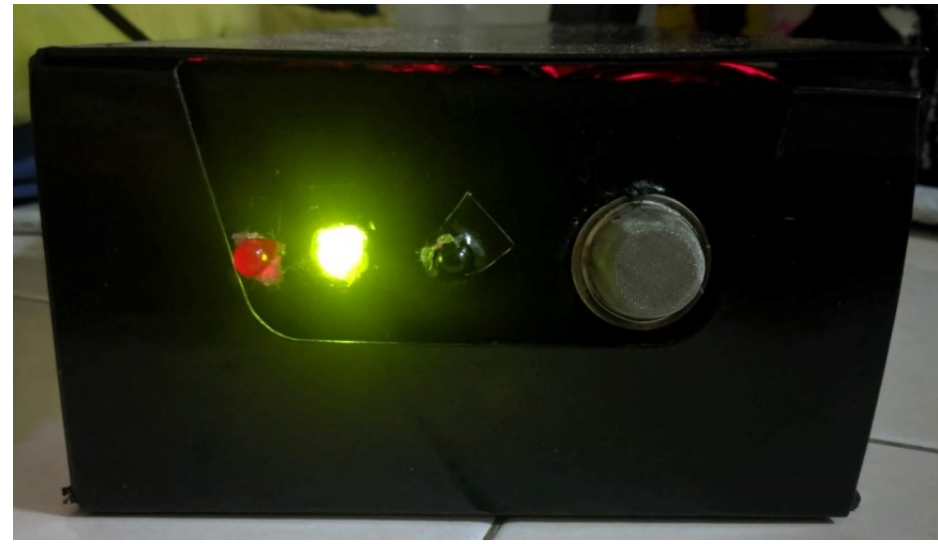

Figure 8. Final Look

\subsubsection{Evaluation}

The evaluation testing is carried out via evaluation survey using Google Form and those who have been tested the research had answered this survey. The following figures are showing the Questions and Responses from the survey.

- Based on Figure 9, 19 over 30 people agreed that Smoke Detector is useful for current and future generation this is because this research can save many lives.

- Based on Figure 10, 24 from 30 respondent agreed that they understand the research very well and the research is easy to use and user friendly.

- Based on Figure 11, 13 of 30 people agreed that this research work properly. All sensor read correct value and the notification work well.

- Based on Figure 12, 21 over 30 respondents agreed that the Smoke Detector's performance is good. This sensor gives fast respond and very sensitive to gas and heat at their environment.

- Based on Figure 13, 17 of them agreed that the Smoke Detector is connected to the internet. This is because the use of NodeMCU to connect the research with internet. 
Mohamad Syafiq Mohamad Adenan, Athirah Nabihah Mas Erwan, Mohamad Norul Hafiz Muzaffar Alfian.

Is this smoke detector with lot notification is useful for current and future generation?

30 responses

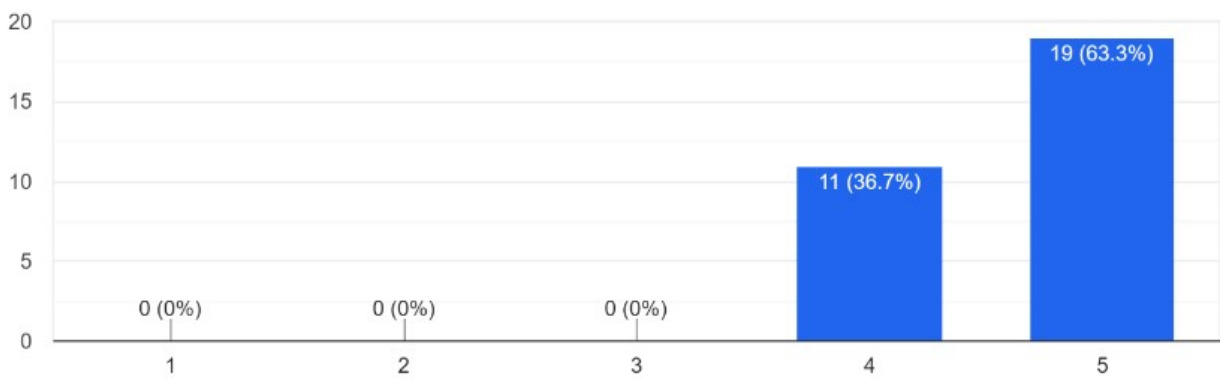

Figure 9. Usefulness int the Future

It was simple to understand and use the project.

30 responses

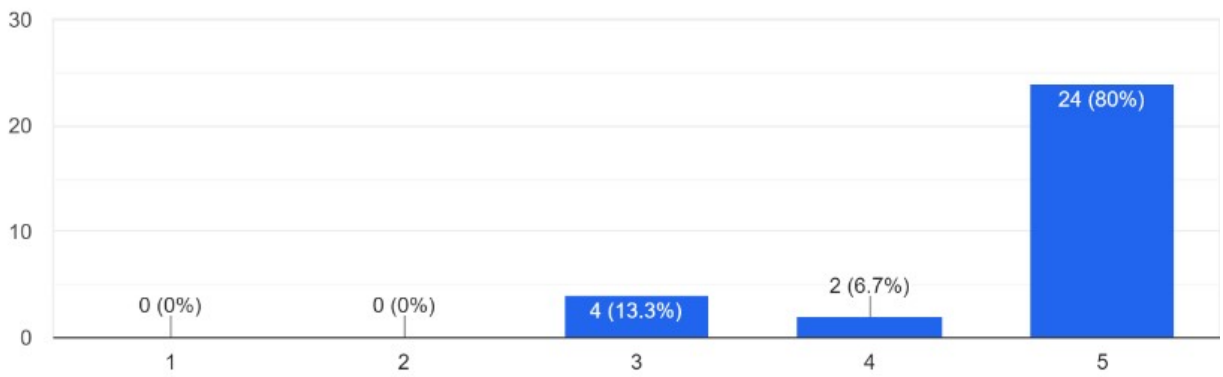

Figure 10. Understanding

Once the sensors detect smoke and fire, user will receives the notification.

30 responses

15

5

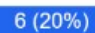

0

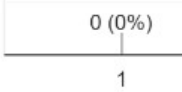

$0(0 \%)$

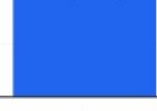

3

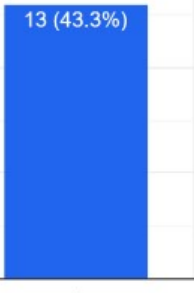

Figure 11. Well Function 
How do you rate the functionality of the system in terms of performance? 30 responses

30

20

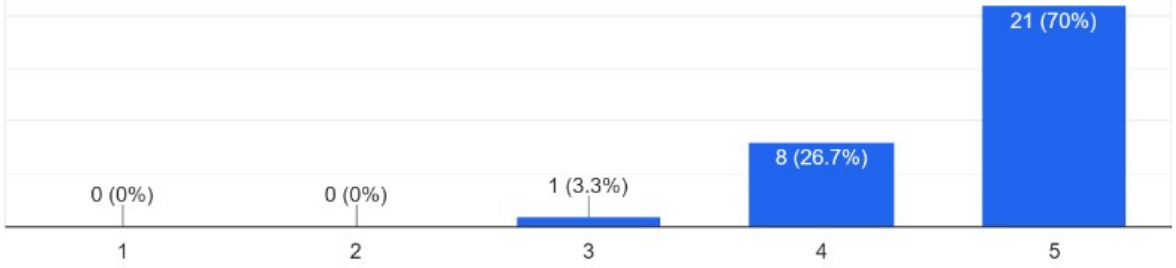

Figure 12. Performance

\begin{abstract}
Is this project connected to internet since it is related to Internet of Things?
\end{abstract} 30 responses

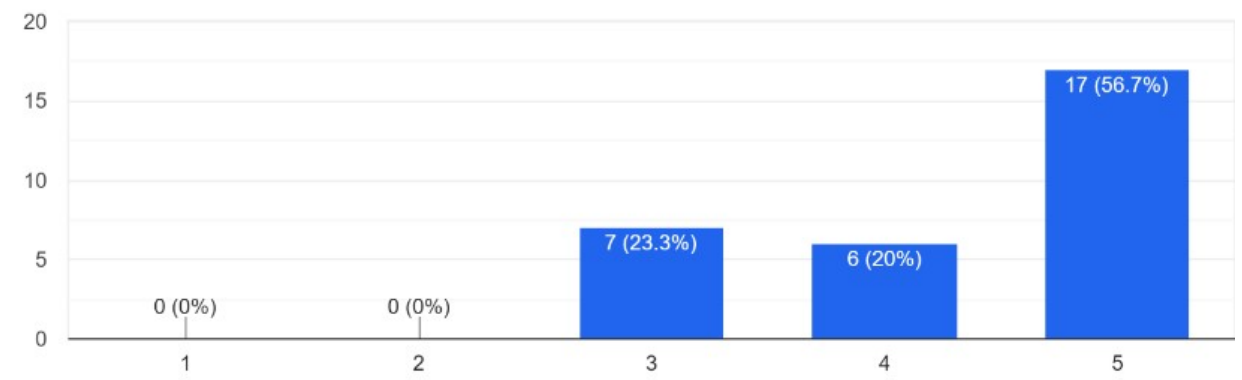

Figure 13. Internet Connection

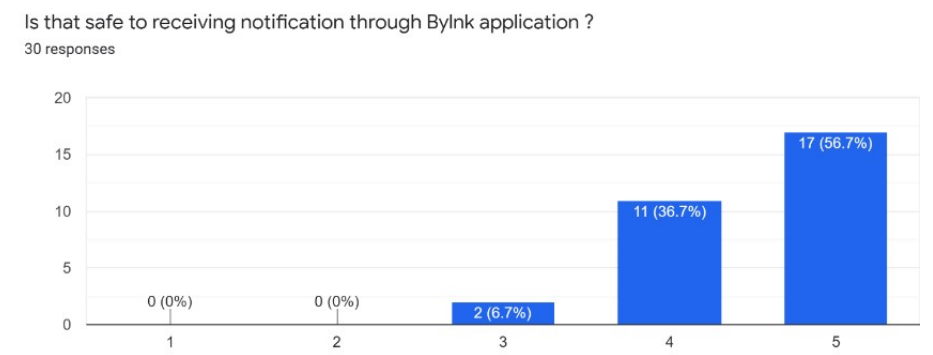

Figure 14. Connection to the blynk app

Based on Figure 14, 17 over 30 people agreed that they can receive notification in their phone through Bylnk app immediately and others respondent get delay on notification. 


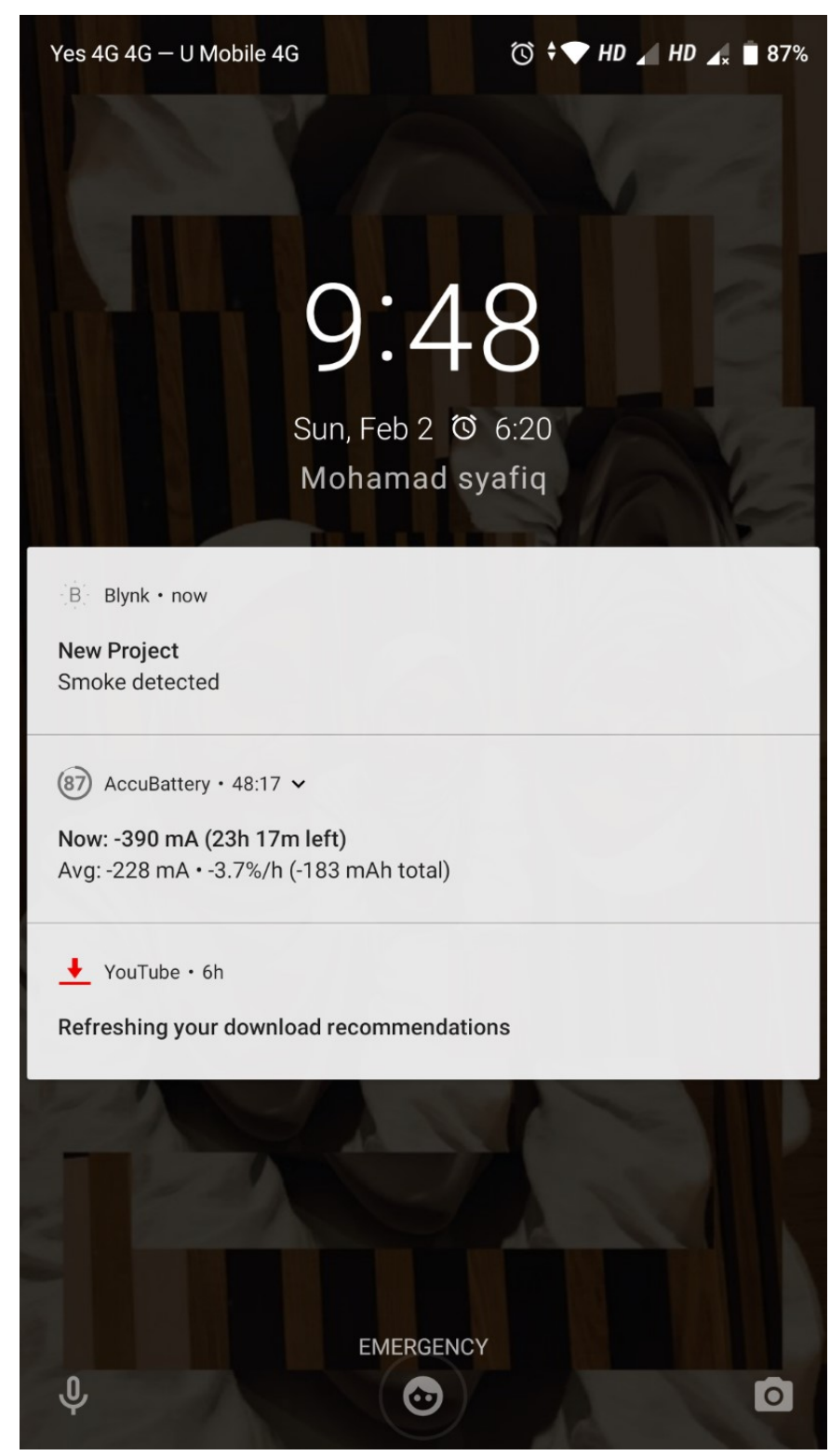

Figure 15. Notification through blynk App

\section{Conclusions}

As the system for the research has been completed, the objectives of the research have been achieved. All the phases that involve needing to achieve the research's aims and objectives will be described in the next few paragraphs.

The first objective of this research is to detect fire, smoke, and gas. Several activities have been done to achieve the first objective. The activities are gathering the requirements, analyze the requirements and lastly document the requirement. All of the activities are done by interacting with distributing the questionnaire, observing the existing application and reviewing the existing documents resulting in delivering the deliverables for the first objective. Next, to design a suitable diagram for the guideline in the development phase. After all, requirements had been collected, it must be proceeded to design phase where the development team can have the guideline on how to build the research and meet the requirement. The next objective of this research is to develop a 
complete system. As the system is completed, the final objective is achieved. Lastly, the research that has been made must be tested to ensure the requirement that been gathered earlier had been reached to give satisfaction to the user who uses the Smoke Detector.

With the objectives have been achieved, the significance of this research can extend in the future. To the researcher who are interested in in continuing this system. There are several suggestions for this system that can be done:

1. Refine the exterior design and repair the building materials, using fireproof and non-flammable materials.

2. Place smoke detectors in high-risk areas such as kitchens and factories.

3. Connect the smoke detector to hear the nearby fire station so they can get a fire alert quickly.

All of the recommendations are recommended as it can enhance the systems to be more efficient and can help with the productivity in the industry and prevent the fire to be bigger.

\section{References}

[1] F. Anwar, R. I. Boby, S. Hussain, M. M. Rashid, and Z. Shaikh, "A Real-time Integrated Fire Detection and Alarm (FDA) System for Network based Building Automation," Indian Journal of Science and Technology, vol. 10, no. 41, pp. 1-14, 2017.

[2] A. Zariman, M. S. Abd Latif, and A. A. Ismail, "Smart Garbage Monitoring", International Journal of Artificial Intelligence, vol. 6, no. 1, pp. 75 - 81, Sep. 2019.

[3] K. B. Azahar, E. E. Sekudan, and A. M. Azhar, "Intelligent Egg Incubator", International Journal of Recent Technology and Applied Science, vol. 2, no. 2, pp. 91-102, Sep. 2020.

[4] A. A. Ismail, M. A. Azizi, and A. Zariman, "Smart Water Level Indicator", International Journal of Recent Technology and Applied Science, vol. 2, no. 1, pp. 48-58, Mar. 2020.

[5] M. H. Husin and I. D. Hisham, "Smart Charger Based on IoT Concept", International Journal of Education, Science, Technology, and Engineering, vol. 2, no. 1, pp. 39 - 44, Jun. 2019.

[6] M. S. Ab Latif, A. A. Ismail, and A. Zariman, "Smart Mirror for Home Automation", International Journal of Recent Technology and Applied Science, vol. 1, no. 1, pp. 1-11, Feb. 2020.

[7] F. A. Ghani and A. Zariman, "Smart Cane based on IoT", International Journal of Education, Science, Technology, and Engineering, vol. 2, no. 1, pp. 12 - 18, Jun. 2019.

[8] M. H. Hazhari, M. A. Azizi, and A. Zariman, "Smart Delivery Agent", International Journal of Recent Technology and Applied Science, vol. 2, no. 1, pp. 36-47, Mar. 2020.

[9] M. A. Azizi and A. Zariman, "Displaying Health Status Based IoT", International Journal of Recent Technology and Applied Science, vol. 2, no. 1, pp. 25-35, Mar. 2020.

[10] N. Saidatin, S. Nurmuslimah, and P. Bagus, "A Design Remote Control System to Feed Birds Using ESP8266”, International Journal of Recent Technology and Applied Science, vol. 2, no. 2, pp. 81-90, Sep. 2020.

[11] Hermansyah, Kasim, and I. K. Yusri, "Solar Panel Remote Monitoring and Control System on Miniature Weather Stations Based on Web Server and ESP32", International Journal of Recent Technology and Applied Science, vol. 2, no. 1, pp. 1-24, Mar. 2020.

[12] R. Frassetto, "Understanding Building Construction Types," Fire Rescue Magazine, 01-Feb-20 12. [Online]. Available: https://firerescuemagazine.firefighternation.com/2012/02/01/under standing-building-construction-types/\#gref. [Accessed: Sept 2020].

[13] R. Angeline and A. Narayanan, "Fire Alarm System Using IoT," International Journal of Innovative Technology and Exploring Engineering (IJITEE), vol. 8, no. 6S3, pp. 110-112, Apr. 2019.

[14] M. S. Reddy and K. R. Rao, "Fire Accident Detection and Prevention monitoring System using Wireless Sensor Network enabled Android Application," Indian Journal of Science and Technology, vol. 9, no. 17, pp. 1-5, 2016.

[15] Anonymous, "IoT based Fire Alarm System using NodeMCU ESP8266," IoT Design Pro, 02Jul-2019. [Online]. Available: https://iotdesignpro.com/researchs/iot-based-fire-alarm-researchusing-esp8266. [Accessed: Sept 2020]. 
[16] Anonymous, "Flame Sensor: Working, Types, and Its Applications," ElProCus. [Online]. Available: https://www.elprocus.com/flame-sensor-working-and-its-applications/. [Accessed: Nov. 2020].

[17] Anonymous, "Blynk MQ2 Smoke Detector Notification Gauge," Viral Science. [Online]. Available: https://www.viralsciencecreativity.com/post/blynk-mq2-smoke-detector-notifica tion-gauge. [Accessed: Sept 2020].

[18] E. Saraswathi, A. Kumar, J. Singh, J. Mohanty, and Y. Mishra, "Arduino Based Home Automation System Using MQTT Protocol Incorporating Internet of Things (IOT)," Journal of Network Communications and Emerging Technologies (JNCET), vol. 8, no. 5, pp. 24-26, May 2018.

[19] N. A. Ismail, P. Y. Hwa, N. I. Mohd Daud, N. A. Mohd Sabri, and S. M. Suhaimi, "IoT Smart Smoke Alarm System," August 2017. [Online]. Available: https://people.utm.my/azman/2017/ 08/23/iot-smart-smoke-alarm-system/. [Accessed: Sept 2020].

[20] Trijalsrimal, "Fire, Gas and Smoke Detector," Hackster.io, Octobrt 2019. [Online]. Available: https://www.hackster.io/trijalsrimal/fire-gas-and-smoke-detector-8241dc. [Accessed: August 2020]. 